UCRL-ID-118974

\title{
Measurement of the Density of Liquid Aluminum-319 Alloy by an X-Ray Attenuation Technique
}

\author{
Patrick M. Smith \\ G.F. Gallegos
}

\section{RECEIVED \\ SFP 201996 \\ OS T I}

November 1994

This is an informal report intended primarily for internal or limited external distribution. The opinions and conclusions stated are those of the author and may or may not be those of the Laboratory.

Work performed under the auspices of the U.S. Department of Energy by the Lawrence Livermore National Laboratory under Contract W-7405-Eng-48.
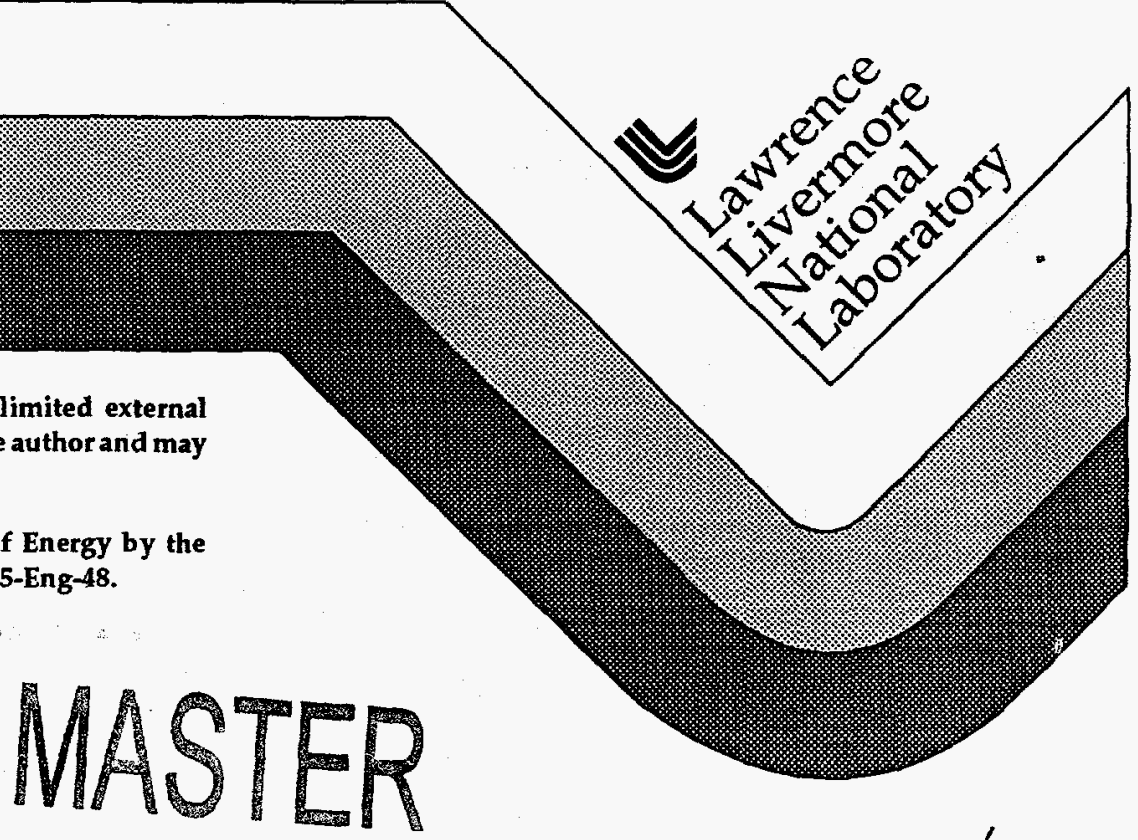

$$
d a
$$




\section{DISCLAIMER}

This document was prepared as an account of work sponsored by an agency of the United States Government. Neither the United States Government nor the University of California nor any of their employees, makes any warranty, express or implied, or assumes any legal liability or responsibility for the accuracy, completeness, or usefulness of any information, apparatus, product, or process disclosed, or represents that its use would not infringe privately owned rights. Reference herein to any specific commercial product, process, or service by trade name, trademark, manufacturer, or otherwise, does not necessarily constitute or imply its endorsement, recommendation, or favoring by the United States Government or the University of Califormia. The views and opinions of authors expressed herein do not necessarily state or reflect those of the United States Government or the University of California, and shall not be used for advertising or product endorsement purposes.

This report has been reproduced directly from the best available copy.

Available to DOE and DOE contractors from the Office of Scientific and Technical Information P.O. Box 62, Oak Ridge, TN 37831

Prices available from (615) 576-8401, FTS 626-8401

Available to the public from the

National Technical Information Service

U.S. Department of Commerce 5285 Port Royal Rd., Springfield, VA 22161

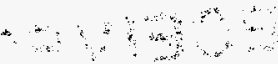




\section{DISCLAIMER}

Portions of this document may be illegible in electronic image products. Images are produced from the best available original document. 


\title{
Measurement of the Density of Liquid Aluminum-319 Alloy by an X-Ray Attenuation Technique
}

\author{
Patrick M. Smith and G. F. Gallegos \\ Lawrence Livermore National Laboratory \\ Livermore, CA 94550
}

\begin{abstract}
Aluminum alloy casting has become an increasingly important field as lighter parts find more widespread use in many areas, especially the transportation industries. As more powerful and inexpensive computers have appearred, simulation of the casting process has become an important part of designing and optimizing processing steps. However, casting simulations cannot hope to accurately describe real processes without the important physical properties of the materials involved in a casting operation.
\end{abstract}

In this study we have constructed a relatively simple apparatus for measuring the density of aluminum-based alloys in the solid and liquid states, at temperatures up to $900^{\circ} \mathrm{C}$. We have measured one of the more important physical properties of a casting alloy, the solidification shrinkage, for a commercial aluminum alloy, Al-319. We find that while the thermal expansion of the alloy in both the solid and liquid states is similar to that of pure aluminum, the density of the liquid alloy is lower than one would estimate by averaging the atomic volumes of the pure liquid components .

Densities were measured by an x-ray attenuation technique originally developed [1] to study density changes in liquid metals that melt at low temperatures, such as $\mathrm{Pb}$. The technique, which has been applied extensively to pure liquid metals and binary alloys [2-9], exploits the change in $x$-ray attenuation accompanying 
changes in density in a sample. When a monoenergetic beam of radiation of intensity $I_{0}$ is incident on a material, the transmitted intensity depends on the density $\rho$, thickness $x$, and absorption coefficient $\mu$ :

$$
I=I_{0} e^{-\mu p x}
$$

As the absorption coefficient is independent of temperature, the dependence of the density on temperature can be extracted by measuring $I$ at various temperatures.

The apparatus constructed to perform these experiments is depicted in figure 1. The $\mathrm{x}$-ray source is a $40 \mathrm{mCi}{ }^{241} \mathrm{Am}$ source, which produces a relatively weak 59.57 $\mathrm{keV} \mathrm{x}$-ray. The beam is collimated by a $3 \mathrm{~mm}$ diameter.steel collimator at the source and by a $12 \mathrm{~mm}$ diameter lead collimator at the detector; the source to detector distance is approximately 1.2 meters. The low energy and intensity of this source allow it to be used with very little shielding.

The aluminum sample is placed in a boron-nitride coated rectangular graphite (ISO-880U) crucible. The crucible walls were $2.00 \pm 0.05 \mathrm{~mm}$ thick, and the boron nitride coating layer added an additional $0.15 \pm 0.03 \mathrm{~mm}$ to the thickness. Boron nitride was chosen as a coating material to prevent adhesion of the aluminum to the graphite during solidification and to prevent reactions between alloy components and the graphite. The crucible is placed in a quartz flash lamp tube furnace, and helium gas is flowed through the tube at 20 liters/hour. The atmosphere inside the tube is contained by two $2 \mathrm{~mm}$ thick aluminum plates at the ends of the tube, and the sample . thickness is $20 \mathrm{~mm}$ (approximately one and a half $1 / e$ skin depths for $60 \mathrm{keV}$-rays in aluminum). This thickness was chosen to balance reasonable data collection times with good sensitivity to changes in the density of the aluminum. Typical count rates were 250 counts/second, with collection times of 20-40 minutes at each temperature.

Absolute measurements of the density of a sample by the gamma attenuation technique require that the incident intensity be known accurately. However, if the 
density of the sample at room temperature is already known, relative changes in the density can be determined without measuring $I_{0}$ directly.

The $\mathrm{x}$-rays arriving at the detector have been attenuated by several components in the apparatus: the aluminum endplates, the graphite crucible walls, the helium gas in the quartz tube, and by the aluminum sample itself. Thus the detected intensity $I$ is:

$$
I=I_{0} e^{-\mu_{\mathrm{Al}} \rho_{\mathrm{pl}} 2 x_{\mathrm{pl}}} e^{-\mu_{\mathrm{C}} \rho_{\mathrm{cr}} 2 x_{\mathrm{cr}}} e^{-\mu_{\mathrm{He}} \rho_{\mathrm{He}} x_{\mathrm{He}}} e^{-\mu_{\mathrm{Al}} \rho_{\text {sample }} x_{\text {sample }}} .
$$

Here $\rho_{\mathrm{cr}}$ and $x_{\mathrm{cr}}$ are the density and thickness of the crucible walls, $\rho_{\mathrm{pl}}$ and $x_{\mathrm{pl}}$ are those of the endplates, $\rho_{\mathrm{He}}$ is the density of the gas in the tube furnace, $x_{\mathrm{He}}$ is the length of the tube, and $\rho_{\text {sample }}$ and $x_{\text {sample }}$ are the density and thickness of the aluminum sample. The absorption coefficient $\mu$ for the sample is either $\mu_{\mathrm{Al}}$ (as shown in equation (2), for pure aluminum) or an average $\mu$ based on the atomic fractions of each alloy component. Comparing the intensities $I_{A}$ and $I_{B}$ measured at two temperatures $T_{A}$ and $T_{B}$ (and assuming that the incident intensity $I_{0}$ does not depend on the sample temperature):

$$
\frac{I_{A}}{I_{B}}=\frac{e^{-\mu_{\mathrm{c}} \rho_{\mathrm{cr}}\left(T_{A}\right) 2 x_{\mathrm{cr}}\left(T_{A}\right)} e^{-\mu_{\mathrm{AI}} \rho_{\mathrm{sample}}\left(T_{A}\right) x_{\text {sample }}\left(T_{A}\right)}}{e^{-\mu_{\mathrm{C} P_{\mathrm{cr}}}\left(T_{B}\right) 2 x_{\mathrm{cr}}\left(T_{B}\right)} e^{-\mu_{A} P_{\mathrm{sample}}\left(T_{B}\right) x_{\text {sample }}\left(T_{B}\right)}} .
$$

The endplate and helium gas terms present in equation (2) have been omitted here for simplicity, as several factors conspire to make them insignificant: 1) the endplate thickness $x_{\mathrm{pl}}$ is quite small $\left.(2 \mathrm{~mm}), 2\right)$ the endplates are well outside the furnace and remain at less than $100^{\circ} \mathrm{C}$, well below the typical sample temperatures of $300-900^{\circ} \mathrm{C}$, and 3) the density $\rho_{\mathrm{He}}$ of helium is very low $\left(0.18 \mathrm{mg} / \mathrm{cm}^{3}\right.$ at 1 atmosphere and room temperature). Although ignoring these terms introduces only a $0.15 \%$ error in the density, the terms were included in our final calculations.

Taking $T_{A}$ to be room temperature and $T_{B}$ the temperature of interest, the density and thickness of the sample and crucible walls are easily measured at $T_{A}$. 
The density and thickness $\rho_{\mathrm{cr}}$ and $x_{\mathrm{cr}}$ of the crucible walls are easily calculated at $T_{B}$ using the linear thermal expansion coefficient $\alpha_{C}$ of graphite:

$$
x_{\mathrm{cr}}\left(T_{B}\right)=x_{\mathrm{cr}}\left(T_{A}\right)\left[\frac{1+\alpha_{C} T_{B}}{1+\alpha_{C} T_{A}}\right] \quad \rho_{\mathrm{cr}}\left(T_{B}\right)=\rho_{\mathrm{cr}}\left(T_{A}\right)\left[\frac{1+\alpha_{C} T_{A}}{1+\alpha_{C} T_{B}}\right]^{3} .
$$

Similarly, for temperatures $T_{B}$ below the melting point of the sample, the density and thickness of the sample can be written in terms of the density and thickness at $T_{A}$ and the linear thermal expansion coefficient $\alpha_{\text {sample: }}$

$$
\rho_{\text {sample }}\left(T_{B}\right) x_{\text {sample }}\left(T_{B}\right)=\rho_{\text {sample }}\left(T_{A}\right) x_{\text {sample }}\left(T_{A}\right)\left[\frac{1+\alpha_{\text {sample }} T_{A}}{1+\alpha_{\text {sample }} T_{B}}\right]^{2}
$$

Substituting equations (4) and (5) into equation (3) leaves only one unknown, $\alpha_{\text {sample }}$, allowing the density $\rho_{\text {sample }}\left(T_{B}\right)$ to be calculated.

Once the aluminum sample melts, it expands to fill the crucible, the inner dimensions of which are known:

$$
x_{\text {sample }}\left(T_{B}\right)=x_{\text {cruc }}\left(T_{A}\right)\left[\frac{1+\alpha_{C} T_{B}}{1+\alpha_{C} T_{A}}\right] .
$$

Here $x_{\text {cruc }}\left(T_{A}\right)$ is the inner dimension of the crucible, measured at room temperature. Upon substitution of equations (4) and (6) into equation (3) we are able to solve for $\rho_{\text {sample }}\left(T_{B}\right)$, the density of the liquid sample.

As this method requires that the density and thickness be known at room temperature, each specimen was machined to a rectangular block shape, measured, . and weighed to determine the room temperature density before melting. The first material studied was pure aluminum (99.99\%). Our measured density for pure liquid aluminum is shown in figure 2 with data reported by others [10-12]. We measure a density of liquid aluminum of $\rho_{\mathrm{Al}}(T)=2.368-2.64 \times 10^{-4}\left(T-660^{\circ} \mathrm{C}\right)$, which is in quite good agreement with previous measurements. The thermal expansion in the solid is also in good agreement with results of other studies [13]. 
We next measured the density of an Al-319 alloy with a composition of $6.61 \%$ $\mathrm{Si}, 3.81 \% \mathrm{Cu}, 0.66 \% \mathrm{Fe}, 0.69 \% \mathrm{Zn}, 0.23 \% \mathrm{Mn}$ and $0.04 \% \mathrm{Ni}$ (percentages are weight $\%$ ), and our measurements are shown in figure 2. Although there is no data available for the density of liquid Al-319, measurements [14] of the thermal expansion in the solid of a similar alloy, Al-319.0, are very similar to ours (see figure 2). While the room-temperature density of our Al-319 is only $2.694 \mathrm{~g} / \mathrm{cm}^{3}$ (3.4\% less than the expected density of $2.79 \mathrm{~g} / \mathrm{cm}^{3}$ [14]), this is a typical amount of porosity in a cast ingot. Although no data exist for the density of liquid Al-319 alloy, an estimate of the density $\bar{\rho}$ can be obtained by averaging the atomic volumes $V_{i}$ and masses $M_{i}$ of each of the constituent elements $i$ in the liquid according to their relative fractional abundances $x_{i}[15]$ :

$$
\bar{\rho}(T)=\frac{\bar{M}}{\bar{V}(T)}=\frac{\sum x_{i} M_{i}}{\sum x_{i} V_{i}(T)} .
$$

While measurements of the densities of most liquid metals exist, the melting temperatures of the minor alloy components (such as $\mathrm{Si}$ and $\mathrm{Cu}$ ) are quite high. Thus the $V_{i}(T)$ used in this calculation are extrapolations of liquid metal density data from much higher temperatures.

The densities measured for pure liquid aluminum and liquid Al-319 are plotted in figure 3 with the expected density calculated using equation (7). Somewhat surprisingly, the liquid appears to be much less dense than expected, indicating that chemical effects have lowered the density of the liquid alloy. We measure a density in the liquid of $\rho_{319}(T)=2.466-3.20 \times 10^{-4}\left(T-660^{\circ} \mathrm{C}\right)$, compared to the calculated density of $\rho_{\text {calc }}(T)=2.506-3.64 \times 10^{-4}\left(T-660^{\circ} \mathrm{C}\right)$. This difference could lead to a sizable underestimation of the solidification shrinkage. Depending on the amount of porosity in the solidified alloy, the estimated shririkage could be as much as $25 \%$ to $55 \%$ lower (for $0 \%$ and $3.4 \%$ porosity, respectively) if the calculated alloy density were used in place of the measured alloy density. 
These density measurements have been made with a relatively simple apparatus containing almost no custom parts. Although the precision of the measurements could be improved with modifications to the equipment, even this simple setup is adequate for measuring aluminum alloy densities in the liquid. In addition, the low-intensity radiation source allows the experiment to be conducted with no special radiation shielding.

The authors thank John W. Elmer for providing pure aluminum samples and for many helpful suggestions, Dick Ryon for supplying x-ray equipment, and Bob Hyland of Alcoa for materials compatibility suggestions.

\section{REFERENCES}

1. G. Döge, Z. Naturforschung 21, 266 (1966).

2. A. S. Basin and A. N. Solov'ev, Zhur. Priklad. Mekh. Tekhn. Fiziki 6, 83 (1967).

3. W. D. Drotning, in Thermal Expansion 6, Ian Peggs (editor), Plenum, New York, (1977), p. 83.

4. V. V. Makeev and P. S. Popel, High Temperature 28, 525 (1990).

5. S. V. Stankus and P. V. Tyagel'skii, High Temperature 30, 594 (1992).

6. W. D. Drotning, Rev. Sci. Instr. 50, 1567 (1979).

7. A. S. Basin and S. V. Stankus, Measurement Techniques 29, 856 (1986).

8. I. Jimbo and J. W. Cramb, Met. Trans. B 24, 5 (1993).

9. S. Hosokawa, S. Yamada and K. Tamura, J. Non-Cryst. Solids 156, 708 (1993).

10. W. J. Coy and R. S. Mateer, Trans. ASM 58, 99 (1965).

11. E. S. Levin, G. D. Ayushina and P. V. Gel'd, High Temperature 6, 416 (1968).

12. S. P. Yatsenko, V. I. Kononenko and A. L. Sukhman, High Temperature 10, 55 (1972).

13. Thermophysical Properties of Matter: Thermal Expansion, Y.S. Touloukian (editor), Plenum, New York (1970), p. 3. 
14. Aluminum and Aluminum Alloys, J. R. Davis (editor), ASM International, Materials Park, Ohio (1993), p. 714.

15. The Physical Properties of Liquid Metals, T. Iida and R. L. Guthrie, Clarendon Press, Oxford, U.K., (1988). 


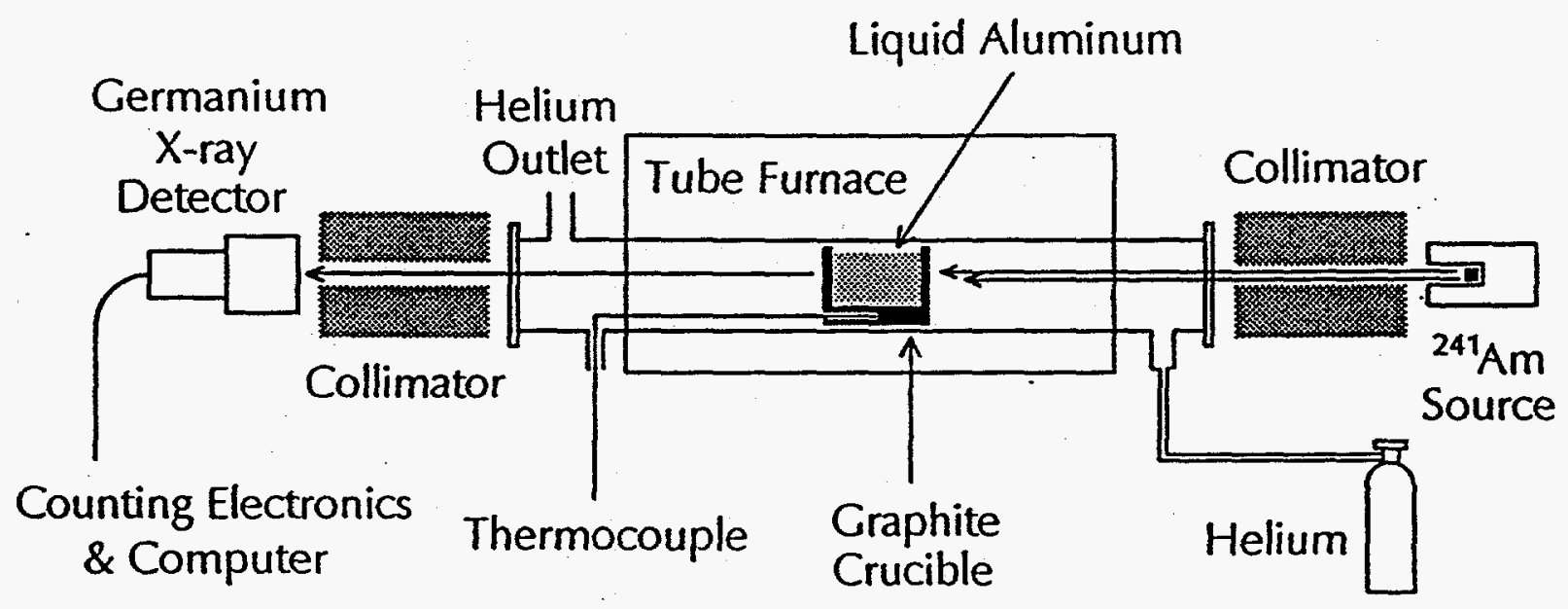

Figure 1: Schematic drawing of the experiment. $60 \mathrm{keV}$ x-rays from a $40 \mathrm{mCi}$ Americium-241 source are collimated before and after passing through the sample, which is contained in a graphite crucible in a quartz tube furnace. Two thin aluminum endplates contain the helium atmosphere in the quartz tube. 


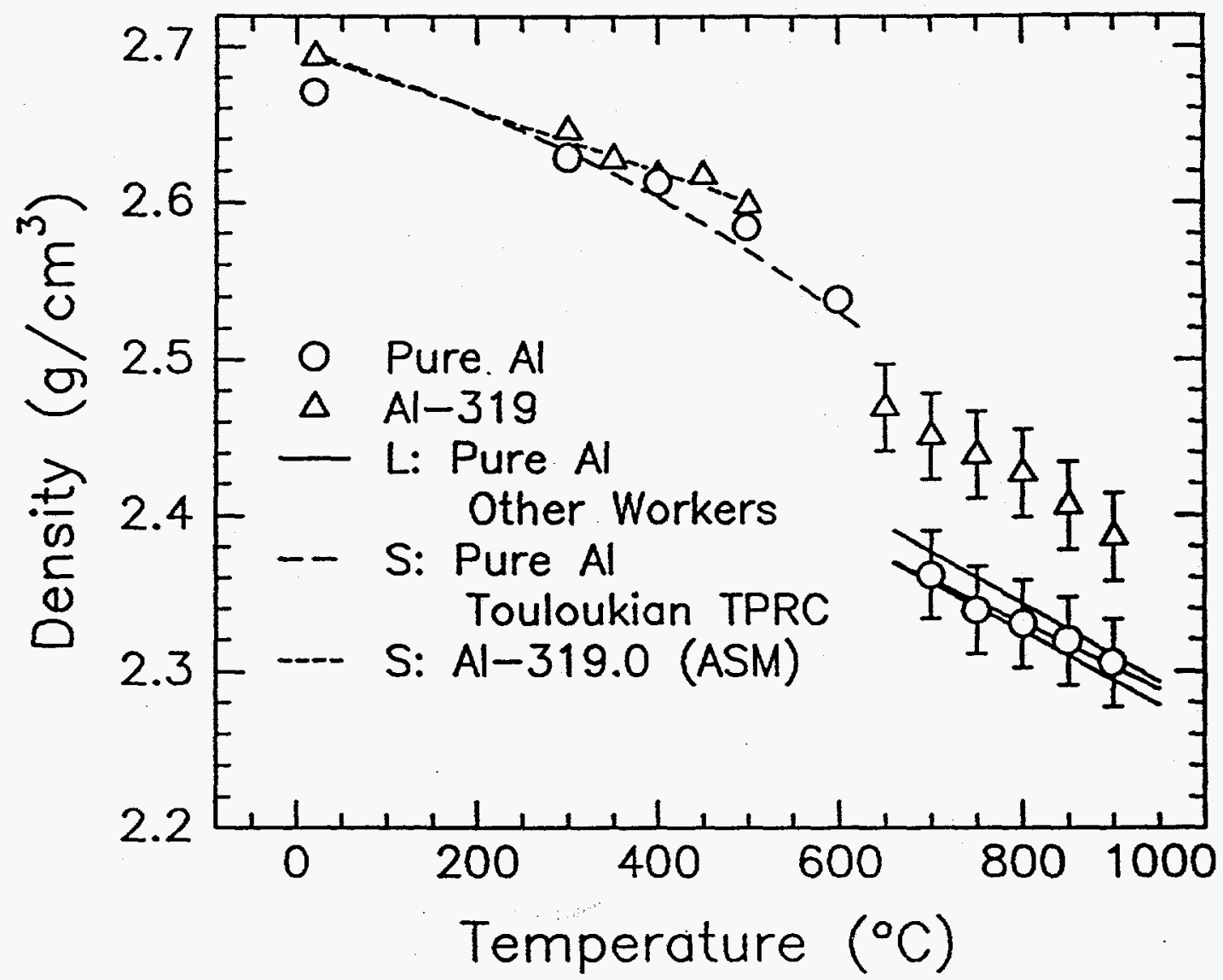

Figure 2: Densities of pure aluminum (circles) and Al-319 alloy (triangles) in the liquid and solid phases measured in this study. The unbroken lines indicate measurements of the density of pure liquid aluminum by other workers [10-12]. The dashed lines show other measurements of the thermal expansion in the solid for pure aluminum and a similar Al-319.0 alloy. Error bars (not shown) for the data points below $600^{\circ} \mathrm{C}$ are approximately one half the size of those for the liquid data. 


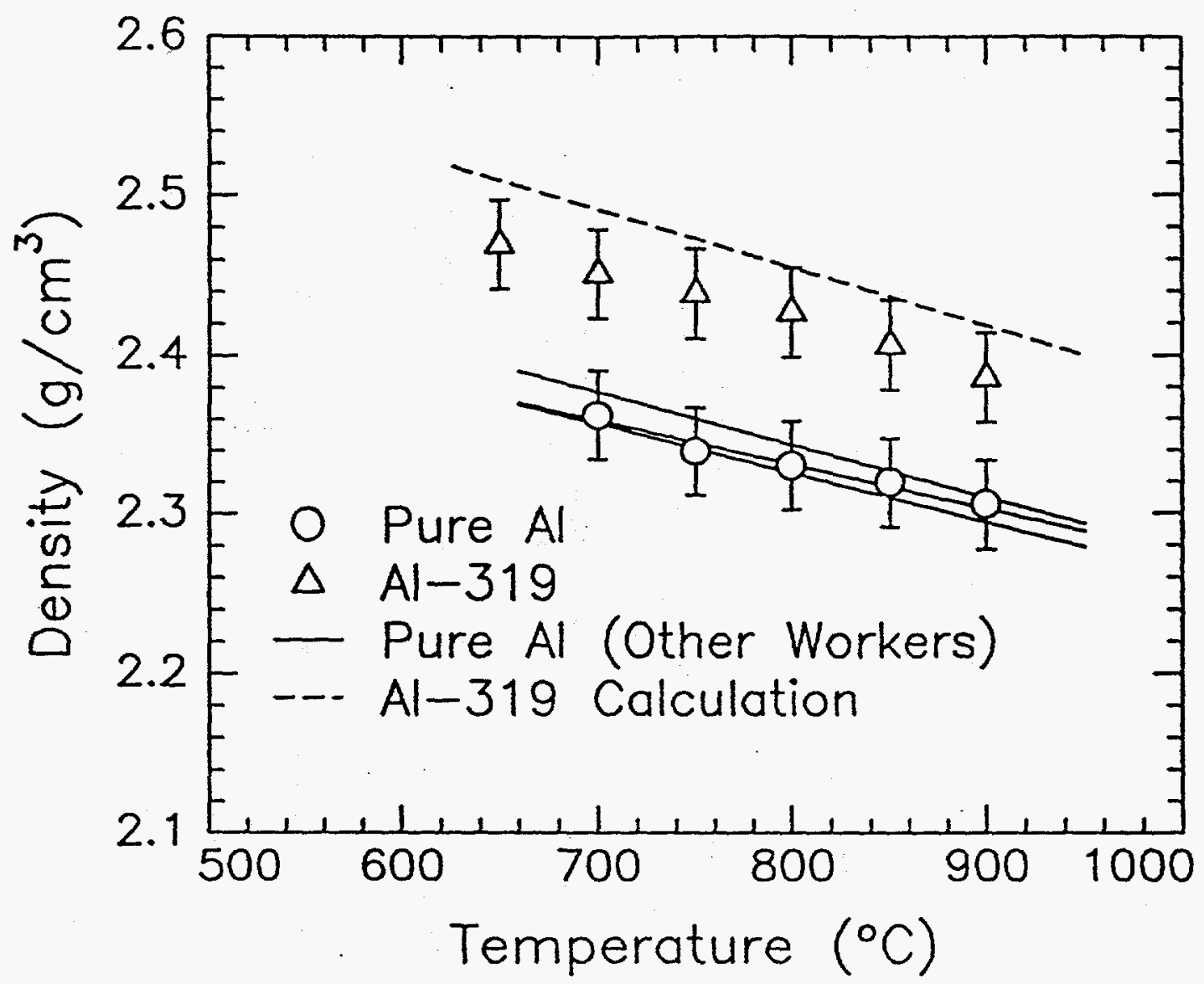

Figure 3: The densities of pure aluminum (circles) and Al-319 alloy (triangles) in the liquid phase compared with measurements of other workers [10-12] (solid lines). The dashed line is an estimate of the density calculated by averaging the liquid atomic volumes of the pure components of the alloy. 